\title{
HIBRIDISMO CULTURAL NOS CURRÍCULOS DA EDUCAÇÃO FÍSICA ESCOLAR*
}

\author{
Éderson Andrade 1 \\ Talita Ferreira ${ }^{2}$ \\ Jaqueline Mendes da Silva ${ }^{3}$
}

\section{Começando a conversa}

A construção curricular da Educação Física é um terreno marcado por disputas de sentidos em torno daquilo que seja melhor para a formação identitária dos estudantes no tocante as práticas corporais e suas intersecções com o mundo. Embora isso seja possível de ser dito é preciso lançar alguns alertas necessários para o debate.

O primeiro é que a disputa dos sentidos nem sempre é marcada por aberturas, ou pela vontade de construir aberturas, mas a disputa muitas vezes enceta na luta contra um inimigo, o que provoca a eliminação, a criação de múltiplos sentidos circulantes na construção curricular. O segundo trata-se do pensamento sobre o próprio corpo, em que se pese a ideia (e prática) de que a Educação Física treina o corpo, fortalece o corpo, higieniza o corpo, padroniza os movimentos do corpo, mas que há possibilidades de se pensar e fazer uma educação física do corpo por inteiro, de culturas que forjam e reforjam os corpos.

Neste sentido o texto tenta conversar sobre a não fixação de currículos da Educação Física a partir de negociações com as culturas dos estudantes.

Por muitos anos, propostas curriculares (ainda não eliminadas) da Educação Física centraram na construção técnico-instrumental do conhecimento. Vimos que os métodos ginásticos, o movimento esportivista, a aproximação da busca pela vida ativa e saudável, modelos motores e psicomotores construíram currículos da Educação Física centrados em

\footnotetext{
* 10.29388/978-65-86678-46-8-0-f.61-76

${ }^{1}$ Doutor em Educação. Professor do Curso de Educação Física do Centro Universitário de Várzea Grande - UNIVAG. E-mail: ederson.andrade@univag.edu.br

${ }^{2}$ Doutoranda em Estudos Culturais. Professora do Curso de Educação Física do Centro Universitário de Várzea Grande - UNIVAG. E-mail: talita.ferreira@,univag.edu.br

${ }^{3}$ Mestra em Educação. Professora do Curso de Educação Física do Centro Universitário de Várzea Grande - UNIVAG. E-mail: jaqueline.santos@univag.edu.br
} 
aspectos técnicos instrumentais, apagando as diferenças culturais atravessadas em cada um dos estudantes na escola (NEIRA, 2011).

Destaca-se que, a partir da década de 1980, os currículos da Educação Física foram abalados por perspectivas críticas e abordagens pedagógicas que foram construídas transformando as práticas em momentos de reflexões. A partir deste período, a cultura adentra o cenário curricular da Educação Física (DAÓLIO, 2004) e abordagens pedagógicas como a crítico superadora, crítico emancipatória, construtivista interacionista, dentre outras, trouxeram novas cores para a tela curricular da área. Embora tais abordagens sejam fundamentais para a Educação Física, de forma geral, pode-se dizer que estas ainda trataram a cultura como um artefato a ser consumido.

A partir dos anos 2000 começamos a perceber a presença de outra perspectiva curricular na Educação Física, em que a cultura não é mais tomada como artefato estático, mas sim, como um processo contínuo de significação. Um dos principais movimentos nesse sentido vem sendo construído por Marcos Garcia Neira e os pesquisadores do seu grupo de pesquisa. Para o autor "o currículo cultural da Educação Física é uma arena de disseminação de sentidos, de polissemia, de produção de identidades" (NEIRA, 2018, p. 09).

É importante salientar a busca pelo que se ensina e sua abertura para as culturas, nas múltiplas abordagens da Educação Física, não se trata apenas de um caminho metodológico a ser seguido aleatoriamente, que se usa e descarta conforme o que se acha, pois cada uma é carregada de sentidos formativos. A partir desse contexto é possível propor, pensar e fazer currículos de Educação Física hibridamente referenciados.

Os processos de hibridação aqui propostos são oriundos dos estudos culturais realizados por Nestor Garcia Canclini (2012). O autor indica que o hibridismo cultural ocorre a partir das desterritorializações, descoleções, a proliferação de gêneros impuros a partir da consideração que não existe um poder local, mas sim, poderes oblíquos. A proposição de um currículo referenciado por processos de hibridação não se trata, no entanto, de uma miscigenação, de uma mistura de abordagens, mas sim, uma forma de conceber os currículos da Educação Física culturalmente referenciados, democraticamente colocados em disputa, construídos em redes.

Dessa forma, este texto discute como ocorrem os processos de hibridação propostos pelo autor citado para, em seguida, propor a construção dos currículos da Educação Física por processos de hibridação, por acreditar que estes processos podem potencializar práticas que pro- 
blematizem as diferenças culturais e suas convivências em um terreno democraticamente plural.

\section{Processos de hibridação na construção curricular}

As múltiplas formas de pensar o currículo, a forma de conceber as políticas curriculares, vêm sendo marcadas por essa efervescência cultural, mostrando as constantes negociações que temos na construção de práticas pedagógicas inovadoras e de políticas, pois a problematização da cultura permite um movimento democrático na construção dos currículos.

Nesse sentido destaca-se agora como estudos curriculares e educacionais, no mesmo caminhar das ciências humanas, vem se destacando e se dedicando a explorar a noção de hibridismo, um conceito caro para compreender as construções curriculares. Para Macedo (2004, p. 13), "trata-se de uma noção que lida com a diferença - assim com a aparente homogeneidade - e perturba tanto as fronteiras entre o eu e o outro quanto à própria ideia de eu e de outro", ou seja, é uma desconstrução dos currículos tradicionais instrumentais e tecnicistas da Educação Física para criar uma possibilidade de transformação cultural.

Nesse sentido, a partir do conceito de hibridismo, como já mencionado, tão caro no cenário curricular, é possível promover outras construções na Educação Física. Busca-se compreender como o hibridismo se desenvolveu e vem se desenvolvendo dentro desses contextos, possibilitando-nos fazer uma leitura menos linear possível das construções curriculares. Esse processo se faz importante para que possamos entender como as compreensões sobre cultura, identidade, diferença, dentre outros conceitos importantes para a educação se reconfiguraram a partir do híbrido (CANCLINI, 2012).

Para Dussel (2005), falar no termo hibridismo requer uma leitura não apriorística, entendendo a complexidade do seu uso em muitas áreas. A autora mostra a partir de uma breve trajetória histórica o uso do termo híbrido, que:

[...] começou a ser utilizado no idioma inglês no século XIX com referência à botânica e à zoologia. Embora presente na literatura desde o século XVII, fortaleceu-se com o impulso classificatório da ciência do século XIX, preocupada em identificar as espécies em taxionomias de conhecimento. Em 1828 no dicionário Webster, o híbrido, era "um mestiço ou mula"; um animal ou planta 
produzido pela mistura de espécies. $\mathrm{O}$ uso do termo aplicado a humanos, data de meados do século XIX. (p. 58).

Canclini (2012) salienta que esse termo é tão antigo como as trocas que as sociedades faziam e fazem entre os seus bens materiais e simbólicos; as migrações e as mestiçagens entre os povos também já se configuravam como híbridos há muito tempo. A diferença entre o antes e o agora reside na velocidade desses processos, pois com o advento das tecnologias, esse processo tem sido cada vez maior.

Alguns outros termos como mestiçagem, sincretismo e crioulização, advindos desde estes tempos continuam a ser utilizados em estudos atuais como formas particulares de hibridação, contudo não dão conta de explicar fusões como culturas de bairros e midiáticas, estilos de consumos, sendo o termo hibridação o mais favorável para nomear os processos políticos sociais na contemporaneidade (CANCLINI, 2011), assim, escolhemo-no para ser utilizado neste estudo, pois o mesmo aproxima-se das produções de políticas públicas culturais.

Uma das potencialidades de pensar e fazer currículos a partir dos processos de hibridação na atualidade é buscar entender que somos sujeitos formados sem determinações fixas, seres impuros, sem predeterminações (DUSSEL, 2005), ou seja, não produzimos uma identidade permanente, mas sim processos de identificações, que se reconfiguram e se hibridizam permanentemente.

Canclini (2011), ao estudar as relações entre Modernidade e PósModernidade na América Latina, traz uma grande contribuição para compreender esse processo de hibridização permanente. A partir de três processos o autor explica como se dá o hibridismo: "a quebra e a mescla das coleções organizadas pelos sistemas culturais, a desterritorialização dos processos simbólicos e a expansão dos gêneros impuros” (p. 284).

A descoleção é uma referência às grandes coleções culturais da Modernidade. A humanidade, ou melhor, o poder constituído na Europa, construiu um grupo de bens simbólicos considerados como a própria configuração da cultura, certos conhecimentos eram tidos como de alta cultura, e quem os detinham eram tidos como os sujeitos cultos, puros. Perceber ainda presentes na contemporaneidade discursos que "tentam" manter as grandes coleções culturais, como a música erudita, o gosto e o acesso a certos quadros pintados por grandes artistas, as grandes Barsas que detinham todo o conhecimento culturalmente correto e verdadeiro. Além disso, pode se ver que existia o discurso do popular, das coleções populares, ligadas às questões folclóricas que mantinham a sua cultura 
com os seus costumes, seus objetos, suas coleções, ou seja, uma visão bipolar entre o culto e o popular (CANCLINI, 2011).

Contudo, estas coleções nunca foram e nunca serão puras, sempre serão produtos de grandes hibridações culturais, e nós mesmos temos a possibilidade de construirmos as nossas próprias coleções, e também podemos a cada momento ressignificá-las, ou seja, as coleções são descolecionadas permanentemente, em que a

[...] agonia das coleções é o sintoma mais claro de como se desvanecem as classificações que distinguiam o culto do popular e ambos do massivo. As culturas já não se agrupam em grupos fixos e estáveis e, portanto, desaparece a possibilidade de ser culto conhecendo o repertório das grandes obras, ou ser popular porque se domina o sentido dos objetos e mensagens produzidos por uma comunidade mais ou menos fechada (uma etnia, um bairro, uma classe). Agora essas coleções renovam sua composição e sua hierarquia com as modas, entrecruzam-se o tempo todo, e, ainda por cima, cada usuário pode fazer sua própria coleção (CANCLINI, 2011, p. 304).

Pensando na produção de práticas curriculares a partir do processo de descolecionar, de quebrar as grandes coleções de saberes, potencializa a construção dos sujeitos que estão em cada espaço-tempo, ou seja, de significação cultural de acordo com as demandas circulantes. Essas descoleções podem romper com hierarquias no tocante à construção de currículos, em que as coleções teóricas tradicionalmente constituintes de um currículo podem ser dissolvidas (LOPES, 2005).

Um segundo processo trazido por Canclini (2011) é a desterritorializ̧ação. A cultura passa a ser significada em suas negociações permanentes nas zonas de fronteiras. A cultura pertencente a um determinado território ou nação se enfraquece. O que se tem como cultural só é construído nas relações entre distintos espaços e tempos entre pessoas que se comunicam cada vez mais com a globalização.

Canclini (2011) aponta que na entrada e na saída da Modernidade existem uma tensão entre a desterritorialização - a perda de uma relação natural da cultura com um determinado território geográfico ou social e a reterritorialização - certas relocalizações assumidas parcialmente entre as velhas e novas produções simbólicas. É um movimento constante que acontece nas tênues linhas fronteiriças.

A desterritorialização acontece principalmente por dois aspectos: a trasnacionalização e o grande fluxo migratório. O primeiro está ligado à 
articulação entre o nacional e o estrangeiro, a cultura produzida em cada país não é consumida e produzida em um único espaço, os cenários são múltiplos e extrapolam fronteiras, esse movimento é marcado por negociações entre os diversos atores sociais que fazem parte desse processo, ou seja, a cultura nunca é pura de um único território. O segundo aspecto liga-se ao grande fluxo de migrações de artistas, escritores e políticos exilados, bem como de toda a população de todos os extratos sociais econômicos (CANCLINI, 2011).

Esses mecanismos permitem que as culturas se toquem e haja permanente troca entre os povos, construindo assim momentos de negociações, uma descoleção de estruturas que tentavam certa fixidez, fato que promove automaticamente novas coleções provisórias e contingentes que se expandem por territórios diversos, ou seja, a cultura é sempre um híbrido, uma mistura, uma significação que acontece a cada novo contato com novos atores sociais.

As construções de currículo nesse sentido são/estão em um constante processo de hibridação, no que se refere à circularidade de múltiplos conceitos, posturas, enfoques (BALL, 2005). Na produção de uma política de currículo via governo, por exemplo, as fronteiras são quebradas e assumem-se posturas de outros lugares, de outros países, de outros estados. Na produção de uma política de currículo na escola as fronteiras também são apagadas e os atores sociais que estão produzindo tal política curricular trazem de vários outros lugares posturas teóricas, concepções de ensino, e outros.

O terceiro mecanismo apresentado pelo autor são os gêneros impuros. Para Canclini (2012) esses são gêneros constitucionalmente híbridos, pois se constituem em pontos de intersecção entre o visual e o literário, o culto e o popular, o artesanal e o industrial. O autor apresenta o grafite e as histórias em quadrinhos como dois gêneros impuros:

O grafite é um meio sincrético e transcultural. Alguns fundem a palavra e a imagem com um estilo descontínuo: a aglomeração de signos de diversos autores em uma mesma parede é como uma versão artesanal do ritmo fragmentado e heteróclito do videoclip (CANCLINI, 2012, p. 338).

A história em quadrinhos mistura gêneros artísticos prévios, consegue que interajam personagens representativas da parte mais estável do mundo - folclore - com figuras literárias e dos meios massivos, introduz em épocas diversas (CANCLINI, 2012, p. 345). 
Os dois exemplos de gêneros impuros, já de nascimento impuros, citados pelo autor são produtos culturais mesclados por formas midiáticas diversas, nos quadrinhos e nos grafites são colocados discursos políticos severos, o drama diário, a sátira da vida, a comédia da vida privada e pública. É importante salientar que a proliferação de gêneros impuros não se trata de uma polarização puro ou impuro, pois não existe pureza. O processo de hibridação acontece por descoleções, por desterritorializações e por gêneros que se constituem ou irão se constituir impuros por estes outros processos.

Esses processos nos elucidam como podem ser constituídos produtos híbridos, que perdem o poder centralizado e verticalizado na significação cultural, o que Canclini (2012) chama de propagação de poderes oblíquos. Há rupturas nas fixações que funcionam como válvulas de escape para a proliferação de culturas híbridas. Para o autor, aparentemente, "os grandes grupos centrados de poder são os que subordinam a arte e a cultura do mercado, os que disciplinam o trabalho e a vida cotidiana" ( $p$. 346), contudo, com uma acuidade ampliada nos mostram que a verticalização nunca é pura, e o poder é sempre oblíquo,

Os cruzamentos entre o culto e o popular tornam obsoleta a representação polar entre ambas as modalidades de desenvolvimento simbólico e relativizam, portanto, a oposição política entre hegemônicos e subalternos, como se se tratasse de conjuntos totalmente diferentes e sempre confrontados (p. 346).

O processo de hibridação visto por essa relação não verticalizada permite analisar as questões do poder, sendo este não eficaz quando mantém uma visão binária entre burgueses sobre proletariados, brancos sobre indígenas, mídia sobre receptores, dentre outros na produção cultural, a eficácia acontece no entrelaçamento de uns com os outros, na obliquidade (CANCLINI, 2012).

A partir dos processos de hibridação os discursos nas práticas pedagógicas reconhecem a fragilidade de um possível/impossível processo de originalidade, pois são rompidas as coleções produzidas historicamente para o processo de ensino, e há produção de novas coleções, os processos de significação nos evidenciam que a cultura e suas fronteiras são frágeis e porosas, ou seja, professores, alunos, gestores, deslocam as fronteiras na produção curricular, bem como consultores contratados para produzirem políticas curriculares via Estado apagam fronteiras no momento de suas escritas, no momento de suas produções, e dessa forma podemos dizer que há uma proliferação dos gêneros impuros (LOPES, 2008). 


\section{Por uma prática hibridizada na construção dos currículos da Educação Física Escolar}

A partir do exposto, a continuidade de nossas reflexões se dá a partir da afirmação de que o poder não é localizado em uma única esfera, que sempre há a proliferação de poderes oblíquos (CANCLINI, 2012). Sendo assim, é possível pensar que o currículo não potente se construído a partir de uma única via, ou pré-definido, por exemplo, em documentos com a base nacional comum curricular. Nessa perspectiva compreendo o currículo da Educação Física como prática de significação cultural (NEIRA, 2018).

Dessa forma pensar e fazer os currículos da Educação Física a partir da leitura e ação dos processos de hibridação enceta para efervescência em um espaço-tempo de luta permanente para significar aquilo que deve ser ensinado em Educação Física. Uma luta dentro de um cenário político radicalmente e pluralmente democrático, ou seja, que reconhece o outro na luta como um adversário e não como um inimigo a ser destruído, que lança no jogo as demandas das diferenças culturais e que problematizam as necessárias construções em torno do reconhecimento da necessária justiça social nos processos formativos dos estudantes (LACLAU; MOUFFE, 2010; MOUFFE, 1996, 2011).

Sendo assim, os currículos da Educação Física podem ser construídos a partir de vários lugares, com múltiplas negociações entre os sujeitos, se afastando de perspectivas técnico- instrumentais para um movimento por vir a ser conhecimentos em Educação Física. Espera-se assim, que o currículo tradicional esportivista de matriz europeia e estadunidense perca seu status e entre em cena práticas corporais vivenciadas e sentidas pelos estudantes, práticas que se farão iguais e diferentes em cada escola.

É preciso o reconhecimento e a problematização de múltiplas entradas e saídas das culturas na escola. É preciso um afastamento continuadamente de perspectivas que fixam os conhecimentos e as práticas em Educação Física, pois existem múltiplas significações em torno do corpo e suas manifestações, suas linguagens, suas gestualidades, suas comunicabilidades. Os currículos da Educação Física construídos por processos de hibridação busca compreender o corpo e suas manifestações, seus códigos, suas linguagens, portanto, não cabe mais a Educação Física se debruçar na formação de corpos saudáveis, máquinas de produção, mas 
sim, aprofundar-se cada vez mais sobre o corpo como texto marcado de significações possíveis de serem construídas pelos estudantes.

O universo das práticas corporais, das lutas, ginásticas, danças, dos esportes, dentre tantas outras manifestações são fruto de permanentes significações, não são fixas, se movem, se transformam. É por isso que este defendemos aqui que tais práticas devem ser pensadas e realizadas por meio das descoleções, desterritorializações, gêneros impuros. E, quanto a isso, preocupamo-nos, neste movimento, ilustrar essa defesa com um relato de experiência de uma aula, talvez, ainda, surgida a partir de um "currículo oculto", mas que pudesse trazer à tona essas ideias de descoleções, desterritorializações e gêneros impuros inseridas em um processo híbrido inovador na Educação Física escolar.

Historicamente, percebe-se que as coleções construídas, são, de um modo geral advindas nos modelos europeus e estadunidense. As coleções foram construídas em torno de esportes clássicos, notadamente futsal, basquetebol, voleibol e handebol, em danças estereotipadas voltadas muitas vezes a aspectos folclóricos tais como as danças das festas juninas, as danças de matriz africanas vivenciadas no dia da consciência negra, os jogos são padronizados e repetidos ao longo dos anos, tais como dama, xadrez, rouba bandeira, as ginásticas (quando dadas) são voltadas para exercícios físicos repetitivos, as lutas se restringem ao trabalho com a capoeira, principalmente no dia da consciência negra.

Essas coleções culturais não são as únicas, a intenção aqui é mostrar, de fato, uma experiência repleta de possibilidades de abalar, desconstruir e reconstruir algumas coleções. Nesse sentido apresentamos a seguir uma experiência vivenciada em torno do que estamos almejando para/na construção dos currículos da educação física: os processos de hibridações nas múltiplas cultuais dos alunos que atravessam as práticas pedagógica no cotidiano escolar, borrando a ideia de dentro dos muros e fora dos muros da escola.

\section{O Manbol como descoleção esportiva e desterritorializa- ção através de fluxo migratório}

O exemplo trazido aqui narra a experiência de uma escola pública no município de Cuiabá-MT em que a escassez de materiais esportivos era marca registrada. Uma professora do curso de Educação Física de uma instituição particular e seus alunotinham como objetivo escolher um 
conteúdo e trabalhar durante um bimestre nesta escola com o conteúdo escolhido a partir do estudo curricular previamente discutido.

A escolha pelo tema "esporte" não surpreendeu, até porque sabese o quão hegemônico ainda é este conteúdo na escola. Entretanto, muitas eram as dificuldades, que iam desde a aceitação dos alunos por temas novos até mesmo pela falta de materiais disponíveis na escola para que posteriormente o trabalho tivesse continuidade. Nesse sentido, algumas perguntas puderam ser feitas de modo a contribuir com essa reflexão em relação a atuação pedagógica dos acadêmicos frente aos desafios comuns nos diferentes espaços escolares. Foram elas: Quais as coleções de conhecimentos da Educação Física estão estabelecidas e fixadas no espaço tempo que eu estou? Quais são as práticas corporais da Educação Física são permanentemente estabelecidas na escola que estou?

Frente aos desafios percebidos, os alunos de Educação Física estenderam a discussão aos alunos da escola como forma de ouvir sugestões que pudessem dar significado, de fato, à prática que seria proposta. Muitas foram as sugestões, entre elas "O bom e velho futsal" como carro-chefe, o voleibol, o basquete, jogos como queimada (que na concepção dos alunos tinha um significado esportivo) e, por fim, um aluno, timidamente, ergueu a mão e sugeriu um esporte do seu Estado de origem, o Pará - o tal esporte era o Manbol.

Em princípio, isso foi motivo de sarro por todos os outros alunos. Piadas e risadinhas devido ao nome da modalidade sugerida foram destiladas e direcionadas ao aluno. Contudo, os acadêmicos, junto a professora responsável, deram voz ao aluno e pediram para que ele explicasse o que vinha a ser esse jogo. $\mathrm{O}$ aluno, mais do que depressa, movido a um certo orgulho de pertencimento diante de sua bagagem cultural latente, explicou aos colegas que era um jogo que surgiu de uma brincadeira comum no Pará - lançamento de mangas (fruto), daí vinha o nome "Manbol".

A história do Manbol, trazida pelo seu idealizador se configura como um esporte que nasceu de uma brincadeira entre dois irmãos, enquanto arremessavam um caroço de manga de um lado para o outro. Esse é o Manbol, que tem sua origem em 1992, quando o paraense Rui Hildebrando, ainda jovem, chamava os amigos para a brincadeira com a fruta, para um tempo depois, criar o nome para o esporte que é a junção das primeiras sílabas de manga (man) e bola (bol).

A partir de uma brincadeira que, aos olhos da cultura, se define claramente como "popular", seu idealizador, anos depois veio a elaborar regras oficias e materiais específicos (no lugar das mangas, duas bolas di- 
ferenciadas - mas, que, coincidentemente, lembram a bola de futebol americano - o que, novamente, traz a ideia da desterritorialização a partir de um processo de transnacionalização) para, então, ser fundada em 2004, a Confederação Brasileira de Manbol (CBM) com o intuito de difundir o esporte em território nacional. Como qualquer manifestação esportiva com regras e constituição própria, o Manbol se tornava oficialmente um esporte nacional, reconhecido em lei estadual como um esporte genuinamente paraense.

Voltando à narrativa sobre a experiência escolar, fato é que, mesmo após as risadas, a curiosidade tomou conta dos alunos do ensino fundamental que, prontamente, aceitaram experimentar o Manbol nas aulas de Educação Física. Os próprios alunos leram e adaptaram as regras tendo a validação e aprovação do colega paraense, que, naquele momento, ganhara uma função importante na aula de Educação Física, uma espécie de consultor esportivo diante da novidade.

Muitas foram as tentativas de encontrar a melhor bola para $\mathrm{O}$ jogo: no primeiro momento, quiseram reproduzir a ideia da manga, entretanto, não utilizaram o caroço apenas, mas tentaram fazer com a própria fruta e, adivinhem? Recusaram a ideia, pois quando as mangas acertavam partes do corpo do adversário, o resultado disso era a dor e, consequente, desaprovação. Assim, partindo de uma ressignificação própria desta comunidade escolar, os próprios alunos fizeram outras tentativas, com: espiga de milho, depois só o sabugo (mas estes se despedaçavam depois de duas ou três sessões) e, por fim, uma aluna disse que sua mãe faria uma capa de tecido para o sabugo, deixando o material mais macio e protegido para que aumentasse a durabilidade do agora, reconstruído equipamento esportivo.

E assim, surgia nesta escola, uma nova coleção esportiva surgida a partir de um processo de desterritorizalização advinda de fluxo migratório dentro do país. A prática esportiva se estendeu para além das aulas de Educação Física, surgindo em meio aos intervalos de aula (recreio) e fazendo com que muitos alunos quisessem construir suas próprias "bolas" de Manbol trazidas na mochila com as mais diversas estampas (de bolas estampadas com logomarcas de "times de futebol" do coração até bolas cobertas com o tecido "chita", remetendo a cultura regional e folclórica mato-grossense do Cururu e Siriri), ampliando assim, de diferentes maneiras as manifestações e focos esportivos pela escola em diferentes tempos e espaços.

As formas de se jogar muitas vezes tão próximas das formas de se praticar esportes podem ser o ponto de partida para jogos totalmente 
desconhecidos nascidos de uma mistura entre o culto e o popular, entre o artesanal e o industrial, como pontua Canclini (2012).

Para além do Manbol, existem tantas outras manifestações e descoleções, em cada escola, em cada comunidade, é possível identificar múltiplas práticas corporais. Os esportes, os jogos, as danças, dentre outras manifestações corporais podem ser vivenciadas pelos estudantes a partir de significações próprias e não como meras reproduções de modelos vigentes e propostos nos currículos afora.

\section{Considerações}

Nossas colocações lançadas aqui parte da defesa de uma educação que permita a formação crítica das pessoas. Uma educação capaz de formar sujeitos para viver cada vez melhor com os outros e com o mundo, o que implica dizer que as demandas das diferenças entram no jogo, as questões de gênero, de sexualidade, de raça, de etnia, dentre outras, estarão presentes na educação enquanto problematização para a formação, escapando de visões estereotipadas, mesquinhas.

Não podemos pensar a formação de sujeitos críticos frente as mazelas do mundo com uma educação tradicional e repetitiva. É preciso pensar em um cenário democrático e libertador que permita a construção de currículos no processo de luta por significação daquilo que deve ser ensinado e aprendido. Os currículos da Educação Física podem contribuir com essa formação quando criados dentro de processos democráticos, que consideram as vidas das pessoas e suas culturas.

Pauta-se, assim, por uma defesa de que os currículos que se constroem em um por vir, com as negociações construídas permanentemente, a partir de processos de hibridação, permitem a avalanche de culturas que atravessam a escola, dando espaço-tempo para a problematização da diferença cultural.

O futebol de rua, o golzinho, o futebol na areia, o gol a gol, o vôlei da rua, na piscina, o skate, os patins, o basquetebol de três, os esportes radicais e de aventura, e muitos outros esportes estão sendo vivenciados, experimentais pelos estudantes, ou seja, outras coleções podem ser formadas. Os estudantes vivenciam danças diversas nos intervalos das aulas, em suas comunidades, e podem entrar no espaço-tempo da Educação Física.

A descoleção pode permitir que se forjem outras práticas corporais que fazem parte das culturas estudantis, mas que estão fora dos currículos da Educação Física. Ela desestabiliza a ordem dada aos esportes 
tradicionalmente estabelecidos nas aulas. Isso não significa apagar os esportes tradicionais, mas de problematizar a construção cultural marcadas nessas práticas e permitir que se tenham outras práticas ainda não vistas, como diz Canclini (2012), é a hora de renovar as composições entrecruzando as culturas permitindo que cada pessoa possa construir suas próprias coleções, que estão abertas a novas descoleções, em um eterno movimento de construir desconstruir construir, permitindo o jogo democrático e a justiça social nos processos formativos dos estudantes.

Nossas coleções sempre serão abaladas, dentre outros aspectos, pelo que Canclini (2012) chama de desterritorialização. Os currículos da Educação Física serão mais profícuos para a formação dos estudantes quando localizamos nas fronteiras aberturas, fissuras, que permitem a circulação das culturas. Aquilo que se vive corporalmente na China, na Finlândia, no Canadá, na Costa Rica, ou em quaisquer outros lugares transita pelo mundo por trasnacionalização e por fluxos migratórios. Isso implica dizer que não podemos os muros das escolas em barreiras intransponíveis, pois por eles vão transitar vivências de outros lugares que os alunos conheceram e outros alunos de outros lugares vão entrar na escola.

Um estudante do Brasil que sabe dançar funk e forró ao fazer uma viagem para a Colômbia pode conhecer a dança mapalé e ao retornar pode trazê-la para o contexto da sua escola no Brasil. Da mesma forma que uma escola que só promove um tipo de dança no currículo da Educação Física pode receber um estudante que veio do Haiti que pode trazer ritmos para as aulas de Educação Física no Brasil. E, ainda, como no relato trazido anteriormente com o Manbol, podemos pensar nos fluxos migratórios que vivemos dentro do nosso país. Os jogos praticados no sul do país podem ser diferentes nos praticados na região norte.

É importante para os currículos da Educação Física sejam construídos sempre por processos de desterritorilização, ou seja, sem fixar as práticas corporais que circulam, que entram e saem dos muros escolares. É preciso tirar do lugar aquilo que se repete perpetuamente e vivencias práticas corporais oriundas de outros lugares, de outros países, de outras regiões, de outras cidades, de outros territórios. É preciso conversar com outros lugares e pensar que as práticas corporais transitam pelos territórios. As fronteiras são porosas, o que permite que as culturas negociam e construam outras práticas corporais tornando os sujeitos consumidores e construtores de culturas.

A proliferação de gêneros impuros, neófitos híbridos (CANCLINI, 2012), podem potencializar a experimentação, a experiên- 
cia, a disseminação de práticas corporais inovadoras, contextuais, democráticas. Ao pensar de forma coletiva entre professores, estudantes, comunidade, em formas de vivenciar as práticas corporais, o currículo da Educação Física pode permitir uma vivência com o corpo por inteiro, permitindo as negociações, as linguagens, as gestualidades, as comunicabilidades, entre as pessoas.

Os currículos da Educação Física construídos por processos de hibridação podem romper com a verticalidade muitas vezes estabelecidas nas escolas. Tal estabilidade gerada por políticas centralizadas, por práticas antidemocráticas, dentre outros aspectos, são desestabilizadas pela descoleção, desterritorialização e pela proliferação de gêneros impuros, potencializando a criação e (re) criação de práticas corporais atravessas pela cor e pelo cheiro das culturas do povo. Essa prática permite que professores e professoras de Educação Física reconheçam e problematizem os conhecimentos dos estudantes dentro de suas múltiplas diferenças culturais.

Considera-se, por fim, que pensar a construção de currículos da Educação Física Escolar por processos de hibridação cultural permite a efetivação de propostas fugidias da fixação tradicional que busca a formação por via padronizadora. Esses processos podem permitir a negociação constante entre os sujeitos, encetando para ampliação dos espaços de criação de projetos de qualidade para a Educação Física, para a escola. Além disso, abrem o terreno para escapar da criação de currículos por etapas, por formas fixas a serem seguidas. Desse modo, ainda se pode crer que os currículos da Educação Física Escolar, construídos por processos de hibridação cultural, serão forjados em um eterno movimento de por vir, permitindo que as culturas corporais sejam sempre significadas e ressignificadas pelos sujeitos que estão na escola, de forma democrática.

\section{Referências}

BALL, S.- Reformar escolas/reformar professores e os terrores da performatividade. Revista Portuguesa de Educação, v. 15, n. 2, 2005

CANCLINI, N. G. Culturas Híbridas: estratégias para entrar e sair da modernidade. $4^{a}$ Ed. São Paulo: Editora da Universidade de São Paulo, 2012

DAOLIO, J. Educação física e o conceito de cultura. Campinas, SP: Autores Associados, 2004. 
DUSSEL, I. O currículo híbrido: domesticação ou pluralização das diferenças? In: LOPES, Alice R. C. e MACEDO, Elizabeth (Orgs.) Currículo: debates Contemporâneos. São Paulo: Cortez, 2002

LACLAU, E; MOUFFE, C. Hegemonía y estratégia socialista: hacia uma radicalizacion de la democracia. 3 ed. Buenos Aires: Fondo de Cultura Económica, 2011.

MACEDO, E. Currículo como espaço tempo de fronteira cultura. Revista Brasileira de Educação, v. 11 n. 32 maio/ago., 2006

MOUFFE, C. En torno a lo político. Buenos Aires: Fondo de Cultura Económica, 2011.

. O regresso do político. Lisboa: Gradiva, 1996.

NEIRA, M. G. Pedagogia da Cultura Corporal. São Paulo: Autores Associados, 2011.

O currículo cultural da educação física: pressupostos, princípios e orientações didáticas. Revista e-Curriculum, São Paulo, v.16, n.1, p. 4 - 28 jan./mar., 2018 
